\title{
Abordaje transdisciplinario en Pediatría a 100 años de nuestra Sociedad
}

\author{
Interdisciplinary approach in Pediatrics at 100 years of the Sociedad Argentina \\ de Pediatría
}

Este año del centenario ha sido fructífero en varios aspectos de la Pediatría, principalmente a través de las múltiples acciones y actividades organizadas por la SAP para reflexionar acerca del pasado y el presente del cuidado de la salud de niños y adolescentes. En cierta medida, el reciente Congreso Internacional realizado en Buenos Aires fue la pieza central de la celebración y asimismo, significó un espacio muy especial al abordar temas de la práctica pediátrica cotidiana, desde una mirada diferente a la habitual, que mayormente se centra en los aspectos biológicos y científicos. La inclusión de numerosos temas relacionados con las ciencias sociales -antropología, sociología, filosofía- como así también la activa participación de profesionales de esas disciplinas, no fue casual y respondió a la imperiosa necesidad de inculcar con mayor esfuerzo un abordaje transdisciplinario en la atención pediátrica (y por cierto en toda medicina). En el Congreso no se describieron enfermedades desde sus aspectos clínicos sino que se buscó ir más allá y llegar a los múltiples aspectos que están "detrás de la enfermedades" que muchas veces no los vemos, no porque estén ocultos, sino porque no actuamos en la forma que nos permita verlos.

En 100 años, muchas cosas sucedieron en la Pediatría; de una disciplina incipiente y aún no bien definida cuando se creaba nuestra Sociedad (de hecho todos los fundadores eran médicos generales y atendían más adultos que niños) llegó a ser una rama bien específica y reconocida de la medicina. También es innegable que en todos estos años se produjeron notables avances médicos que fueron reduciendo la mortalidad y morbilidad de muchas enfermedades en los niños. Este aspecto es irrefutable y no me extenderé en él, pero sí deseo señalar que, como sucede en otras áreas del quehacer humano, los progresos siempre tienen un costo, no referido al monetario, y cuando ese costo es demasiado alto e incluso supera los posibles beneficios, comienzan a surgir problemas, que de no ser reconocidos y limitados tienden a incrementarse y asimismo, a generar nuevos problemas.

Vivimos una era marcada por un apabullante e incesante desarrollo tecnológico que alcanzó logros importantes y beneficiosos, pero así mismo creó nuevos dilemas que desafían las condiciones y las formas de vida del ser humano. Este desarrollo motivó que en muchos creciera la idea, hoy prácticamente generalizada, que lograr una vida "cada vez mejor" depende mayormente de la tecnología. Esto influye perniciosamente en la gente, y en nuestra profesión puede tener consecuencias nefastas. Raúl J. Usandivaras, prestigioso psiquiatra argentino decía, en un Editorial de la Revista Medicina en 1986, algo que apoya a definir como irreal la creencia de los grandes beneficios de la era tecnológica: "los cambios que ha sufrido la humanidad en este mismo siglo confirman la caída de la ilusión, de la felicidad que iba a traer aparejada los avances de la tecnología. Es el fin de un paradigma que parecía venturoso".

En la medicina, estos efectos se vieron reflejados en sustanciales cambios, pero tal vez donde más han influido es en la atención de los pacientes. Parecería que un resultado satisfactorio solo se puede lograr a través de la tecnología, y si es nueva, mejor. Este equivocado enfoque deja de lado el hecho de que se pueden alcanzar progresos significativos en el cuidado de la salud y en el bienestar de la población sin ninguna tecnología especial, solo siguiendo los aspectos esenciales y ancestrales de la medicina basados en la solidaridad y a través de una empática y profunda relación con los pacientes.

Es indudable que uno de los mayores problemas actuales en la medicina es la alteración sufrida en el acto médico por excelencia que es la relación con el paciente, no solo debido al encandilamiento tecnológico, que empequeñece todo lo mucho que representa el progreso científico y devalúa cada vez más el humanismo y el arte de la profesión médica.

El insuficiente conocimiento de los aspectos sociales que hacen a la vida de nuestros pacientes, dificulta la comprensión de los múltiples factores que rodean a las enfermedades.

Como señalé, en el Congreso del Centenario pudimos ver y comprobar, entre muchos otros aspectos, cómo la interacción con disciplinas sociales íntimamente relacionadas con la medicina nos podrá ayudar a tener una mirada que no esté centrada en lo estrictamente biológico; sino que consideremos en todo momento aquello que nos permita conocer las necesidades de los pacientes, es decir, sus sentimientos, sufrimientos, deseos, esperanzas...

José M. Ceriani Cernadas Editor

doi:10.5546/ aap.2011.386 